\title{
OPEN Platelet-activating factor (PAF) strongly enhances contractile mechanical activities in guinea pig and mouse urinary bladder
}

\author{
Ge Liu, Mizuki Kaneko, Kento Yoshioka, Keisuke Obara ${ }^{\bowtie}$ \& Yoshio Tanaka
}

In this study, we investigated the effects of platelet-activating factor (PAF) on the basal tone and spontaneous contractile activities of guinea pig (GP) and mouse urinary bladder (UB) smooth muscle (UBSM) tissues to determine whether PAF could induce UBSM tissue contraction. In addition, we examined the mRNA expression of the PAF receptor, PAF-synthesizing enzyme (lysophosphatidylcholine acyltransferase, LPCAT), and PAF-degrading enzyme (PAF acetylhydrolase, PAF-AH) in GP and mouse UB tissues using RT-qPCR. PAF $\left(10^{-9}-10^{-6} \mathrm{M}\right)$ strongly enhanced the basal tone and spontaneous contractile activities (amplitude and frequency) of GP and mouse UBSM tissues in a concentration-dependent manner. The enhancing effects of PAF $\left(10^{-6} \mathrm{M}\right)$ on both GP and mouse UBSM contractile activities were strongly suppressed by pretreatment with apafant (a PAF receptor antagonist, GP: $10^{-5} \mathrm{M}$; mouse: $3 \times 10^{-5} \mathrm{M}$ ). The PAF receptor (Ptafr), LPCAT (Lpcat1, Lpcat2), and PAF-AH (Pafah1b3, Pafah2) mRNAs were detected in GP and mouse UB tissues. These findings reveal that PAF strongly enhances the contractile mechanical activities of UBSM tissues through its receptor and suggest that the PAF-synthesizing and -degrading system exists in UBSM tissues. PAF may serve as both an endogenous UBSM constrictor and an endogenous mediator leading to detrusor overactivity.

Platelet-activating factor (PAF) is a powerful mediator of inflammation and allergies. PAF was first discovered as a platelet agglutinin in $1972^{1}$, and its chemical structure was determined to be acetyl glyceryl ether phosphorylcholine in $1980^{2}$. In vivo and in vitro experiments clarified that PAF induces not only the aggregation and activation of platelets and leukocytes but also many various biological activities such as increasing vascular permeability, reducing cardiac output, and lowering blood pressure ${ }^{3}$. Furthermore, since the 1980s, PAF has been reported to be able to relax or contract various smooth muscle (SM) tissues. For example, (1) PAF relaxes rat thoracic/ pulmonary/mesenteric artery SMs and ferret pulmonary artery in an endothelium-dependent manner ${ }^{4-7}$, and (2) PAF contracts human/rat/guinea pig (GP) tracheal and bronchial SMs ${ }^{8-10}$, rat gastric fundus $\mathrm{SM}^{11}$, GP ileal $\mathrm{SM}^{12,13}$, rat colonic $\mathrm{SM}^{14}$, and pregnant human/rat/GP uterine $\mathrm{SM}^{15-17}$. Thus, PAF exerts contractile effects on SMs of the respiratory, digestive, and genital organs, as well as relaxing effects on SMs of vessels in an endotheliumdependent manner.

PAF is produced not only in inflammatory cells such as eosinophils and neutrophils ${ }^{18}$ but also in cardiomyocytes, vascular endothelial cells, and urothelial cells that are not directly involved in inflammation ${ }^{19-22}$. Recently, the accumulation of PAF caused by smoking was reported in urinary bladder (UB) microvascular endothelial cells and urothelial cells, which suggests that PAF plays an important role in the development of chronic inflammatory UB diseases, such as interstitial cystitis and UB pain syndrome $e^{21,22}$. Additionally, the accumulation of PAF was significantly higher in isolated urothelial tissues from bladder cancer patients than in normal human urothelial tissues, and PAF expression was markedly increased in high-grade tumors compared with low-grade tumors ${ }^{23}$. These findings suggest that increased PAF production in urothelial cells is associated with lower urinary tract diseases. However, to the best of our knowledge, the effects of PAF on UBSM contractile mechanical activities have not been examined to date.

In this study, we investigated the effects of PAF on the basal tone and spontaneous contractile activities of UBSM tissues to determine whether PAF enhances the contractile mechanical activities of UBSMs. To confirm that the effect of PAF occurs irrespective of animal species, we used GPs, which exhibit similar lower urinary 
a

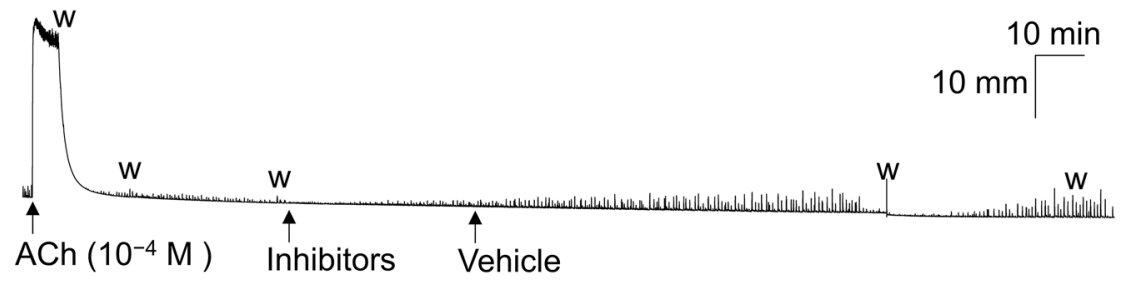

b

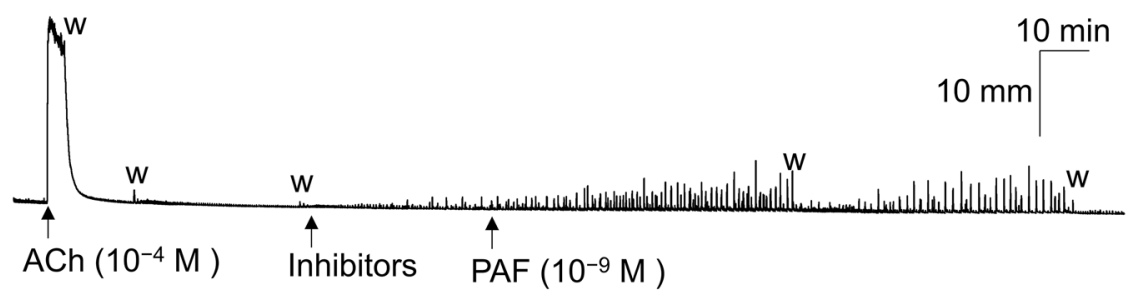

C

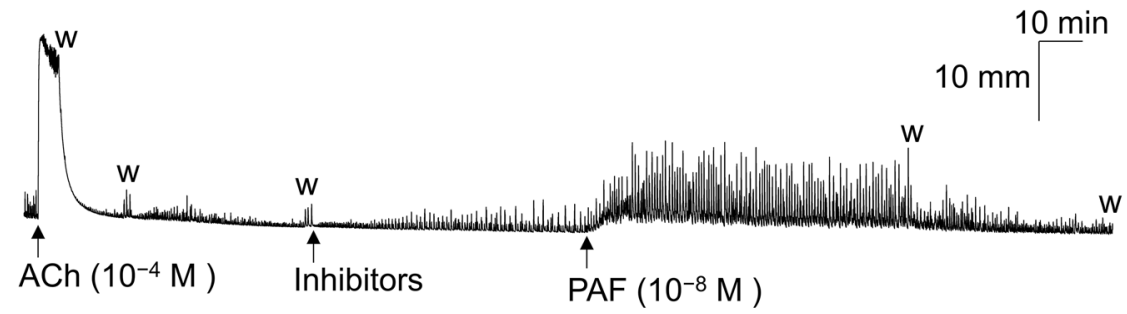

d

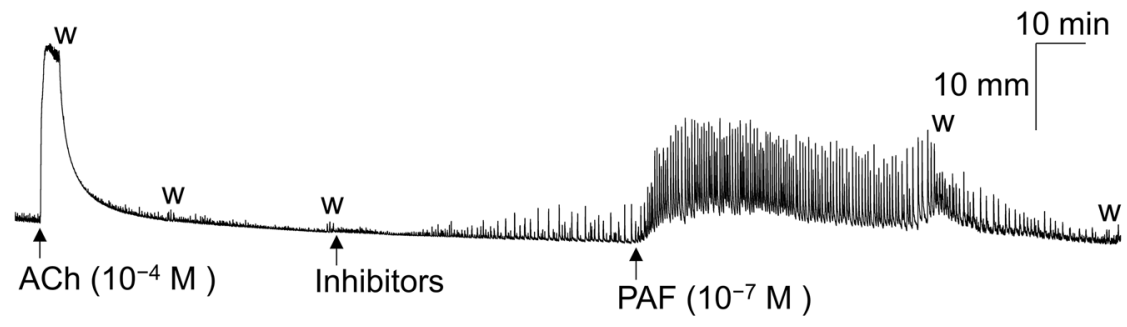

e

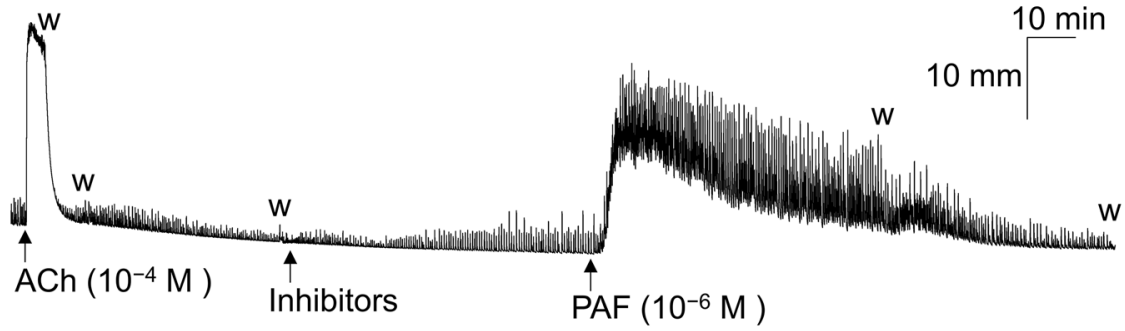

Figure 1. Representative traces showing the contractile response of acetylcholine $\left(\mathrm{ACh}, 10^{-4} \mathrm{M}\right)$ and the effects of PAF $\left[10^{-9} \mathrm{M}(\mathbf{b}) ; 10^{-8} \mathrm{M}(\mathbf{c}) ; 10^{-7} \mathrm{M}(\mathbf{d}) ; 10^{-6} \mathrm{M}(\mathbf{e})\right]$ and its vehicle $[0.25 \%$ bovine serum albumin (BSA) (a) $]$ on the basal tone and spontaneous contraction activities in isolated guinea pig urinary bladder smooth muscle. Inhibitors: atropine $\left(10^{-6} \mathrm{M}\right)$, suramin $\left(10^{-4} \mathrm{M}\right)$, phentolamine $\left(10^{-6} \mathrm{M}\right)$, propranolol $\left(10^{-6} \mathrm{M}\right)$, tetrodotoxin $\left(3 \times 10^{-7} \mathrm{M}\right)$, anti-foam $(0.5 \%)$, and BSA $(0.25 \%)$. $w$ wash out, $P A F$ platelet-activating factor.

tract anatomy and urodynamic profile of micturition to those of humans ${ }^{24}$, and mice, for which exist various disease models. We also examined mRNA expression of the PAF receptor, PAF-synthesizing enzyme [lysophosphatidylcholine acyltransferase (LPCAT)], and PAF-degrading enzyme [PAF acetylhydrolase (PAF-AH)] in GP and mouse UB tissues to further understand whether PAF acts as an endogenous regulator of UBSM mechanical activities.

\section{Results}

Effects of PAF on GP UBSM basal tone and spontaneous contractile activities. Figure 1 and 2 show typical experimental traces (Fig. 1) and quantified results (Fig. 2) of the effects of PAF $\left(10^{-9}-10^{-6} \mathrm{M}\right)$ and its vehicle $[0.25 \%$ bovine serum albumin (BSA)] on GP UBSM basal tone (Fig. 2a) as well as the amplitude (Fig. 2b) and frequency (Fig. 2c) of spontaneous contractile activities. To exclude the possible involvement of parasym- 

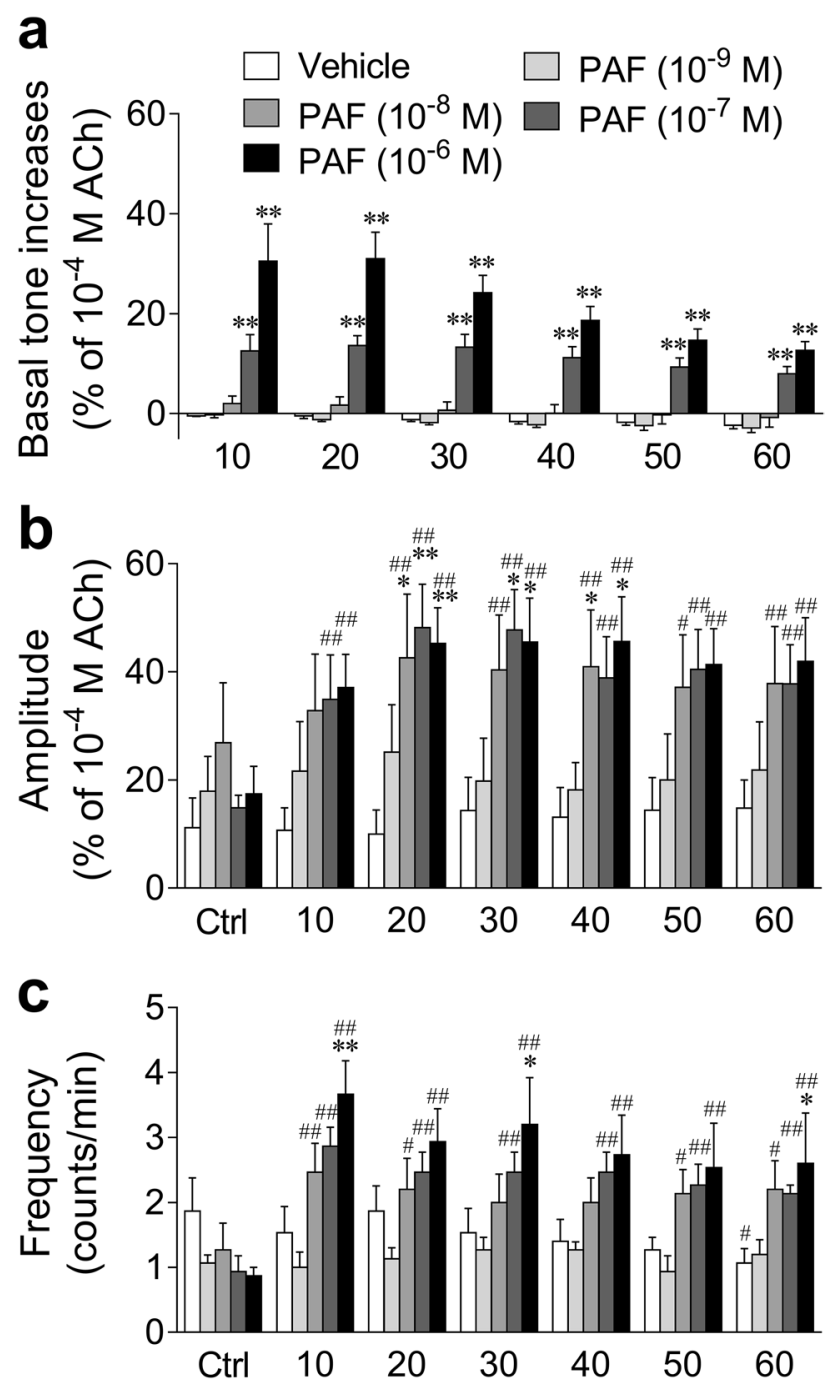

Figure 2. Summarized data of the effect of $\operatorname{PAF}\left(10^{-9}-10^{-6} \mathrm{M}\right)$ and its vehicle $(0.25 \%$ bovine serum albumin $)$ on the basal tone (a) and amplitude (b)/frequency (c) of spontaneous contractions in the isolated guinea pig urinary bladder smooth muscle shown in Fig. 1. Basal tone increases show basal tone changes before and after administration of PAF or its vehicle (a). Spontaneous contraction activities analyzed over 3 min during the following periods were calculated: immediately before administration of PAF or its vehicle (Ctrl, control); 7-10 $\min (10), 17-20 \mathrm{~min}(20), 27-30 \mathrm{~min}$ (30), 37-40 $\min$ (40), 47-50 $\mathrm{min}$ (50), and 57-60 $\min (60)$ after administration of PAF or its vehicle $(\mathbf{b}, \mathbf{c})$. Data are expressed as the means \pm SEM (each $n=5) .{ }^{\star} P<0.05$; ${ }^{* *} P<0.01$ vs. the corresponding vehicle value; ${ }^{\#} P<0.05$; ${ }^{\# \#} P<0.01$ vs. the corresponding control value (two-way ANOVA followed by Dunnett's test). PAF platelet-activating factor, ACh acetylcholine.

pathetic nerve- and sympathetic nerve-derived neurotransmitters [acetylcholine (ACh), ATP, and noradrenaline (NA)], a muscarinic receptor antagonist [atropine $\left(10^{-6} \mathrm{M}\right)$ ], purine P2X receptor antagonist [suramin $\left(10^{-4} \mathrm{M}\right)$ ], adrenoceptor antagonists [phentolamine $\left(10^{-6} \mathrm{M}\right)$ and propranolol $\left(10^{-6} \mathrm{M}\right)$ ], and $\mathrm{Na}^{+}$channel inhibitor [tetrodotoxin (TTX) $\left(3 \times 10^{-7} \mathrm{M}\right)$ ] were included in the experiment. The PAF vehicle $(0.25 \% \mathrm{BSA})$ did not substantially affect the basal tone and spontaneous contractile activities of the GP UBSM (Figs. 1a, 2). In contrast, PAF $\left(10^{-9}-10^{-6} \mathrm{M}\right)$ was found to increase GP UBSM mechanical activities in a concentration-dependent manner (Figs. 1b-e, 2). GP UBSM basal tone was remarkably increased by PAF at $10^{-7} \mathrm{M}$ and $10^{-6} \mathrm{M}$. However, this enhancing effect on GP UBSM basal tone persisted for $<60 \mathrm{~min}$ and tended to start decreasing $\sim 20-30 \mathrm{~min}$ after PAF administration (Figs. 1d,e, 2a). In contrast, the enhancing effects of PAF on GP UBSM spontaneous contractile activities were sustained for 60 min (Figs. 1, 2b,c). In addition, when the experiment shown in Figs. 1 and 2 (isotonic recording) was performed using the isometric recording (Supplementary Figs. 1 and 2), PAF strongly enhanced both basal tone and spontaneous GP UBSM mechanical activities.

Effects of PAF on mouse UBSM basal tone and spontaneous contractile activities. Figures 3 and 4 show typical experimental traces (Fig. 3) and quantified results (Fig. 4) of the effects of PAF $\left(10^{-9}-10^{-6} \mathrm{M}\right.$ ) and its vehicle (0.25\% BSA) on mouse UBSM basal tone (Fig. 4a), as well as the amplitude (Fig. $4 \mathrm{~b}$ ) and frequency 
a

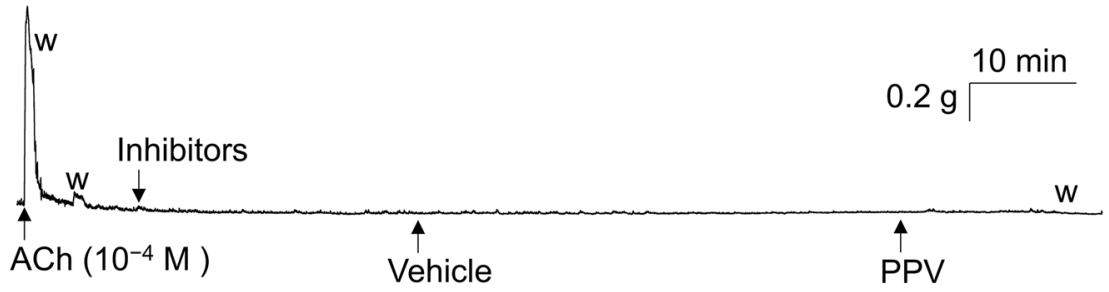

b

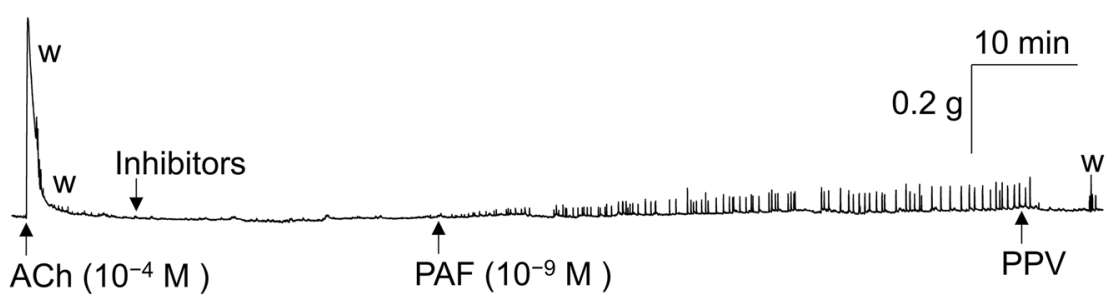

C

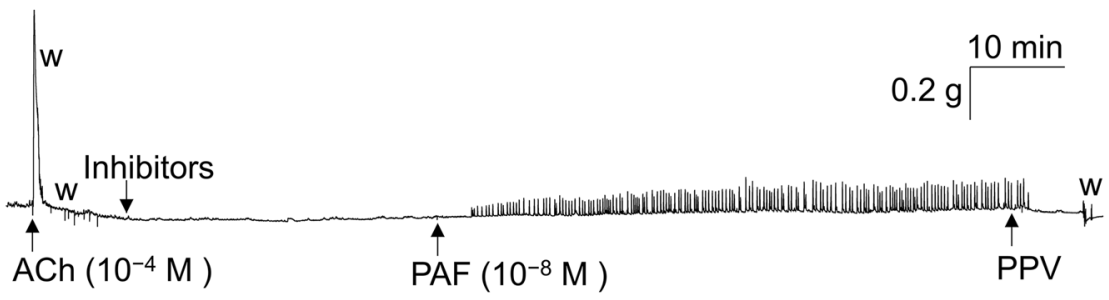

d

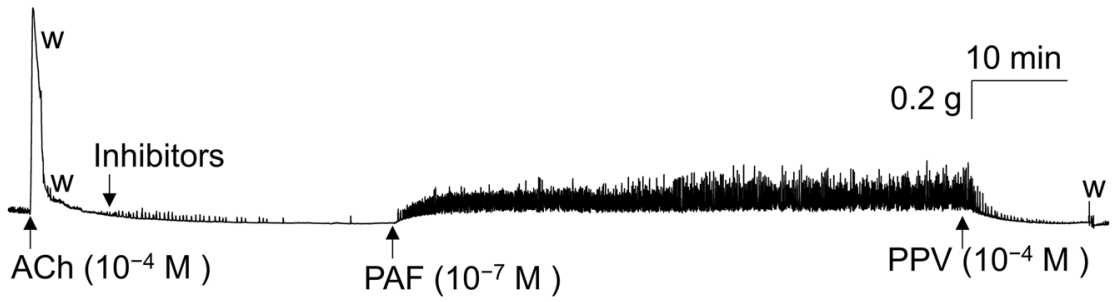

e

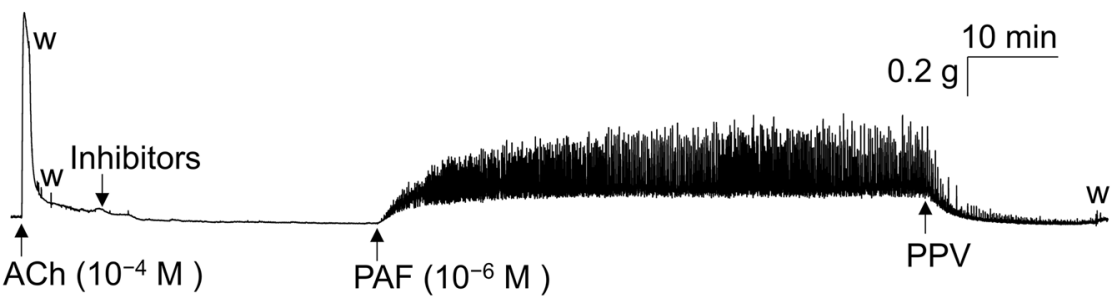

Figure 3. Representative traces showing the contractile response of acetylcholine $\left(\mathrm{ACh}, 10^{-4} \mathrm{M}\right)$ and the effects of PAF $\left[10^{-9} \mathrm{M}(\mathbf{b}) ; 10^{-8} \mathrm{M}(\mathbf{c}) ; 10^{-7} \mathrm{M}(\mathbf{d}) ; 10^{-6} \mathrm{M}(\mathbf{e})\right]$ and its vehicle $[0.25 \%$ bovine serum albumin (BSA) (a)] on the basal tone and spontaneous contraction activities in isolated mouse urinary bladder smooth muscle. Inhibitors: atropine $\left(10^{-6} \mathrm{M}\right)$, suramin $\left(10^{-4} \mathrm{M}\right)$, phentolamine $\left(10^{-6} \mathrm{M}\right)$, propranolol $\left(10^{-6} \mathrm{M}\right)$, tetrodotoxin $\left(3 \times 10^{-7} \mathrm{M}\right)$, anti-foam $(0.5 \%)$, and BSA $(0.25 \%) . P P V$ papaverine $\left(10^{-4} \mathrm{M}\right), w$ wash out, $P A F$ platelet-activating factor.

(Fig. 4c) of spontaneous contractile activities. This study was also carried out in the presence of the antagonists and inhibitors described in the previous section. The PAF vehicle $(0.25 \% \mathrm{BSA})$ did not substantially affect basal tone and spontaneous contractile activities of mouse UBSM (Figs. 3a, 4). In contrast, PAF $\left(10^{-9}-10^{-6} \mathrm{M}\right)$ was found to increase mouse UBSM mechanical activities in a concentration-dependent manner (Figs. 3b-e, 4). The enhancement of mouse UBSM mechanical activities was sustained for 60 min (Figs. 3, 4).

Effects of apafant on UBSM basal tone and spontaneous contractile activities enhanced by PAF. Figure 5 shows typical experimental traces (Fig. 5a,b) and quantified results (Fig. $5 \mathrm{c}-\mathrm{e}$ ) of the effects of apafant (a PAF receptor antagonist, $10^{-5} \mathrm{M}$ ) on GP UBSM basal tone (Fig. $5 \mathrm{c}$ ), as well as the amplitude (Fig. 5d) and frequency (Fig. 5e) of spontaneous contractile activities enhanced by PAF $\left(10^{-6} \mathrm{M}\right)$. The enhancing effects of 

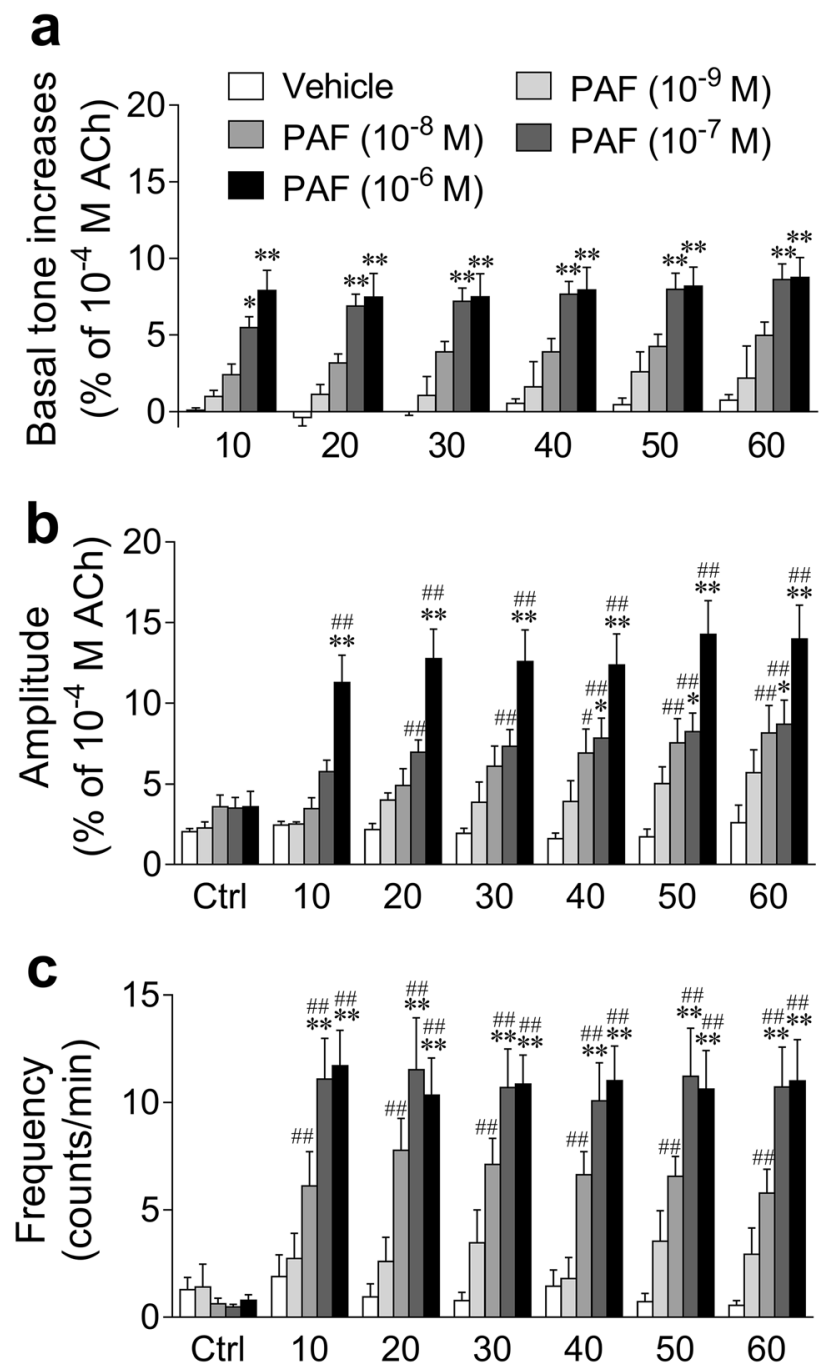

Figure 4. Summarized data of the effect of $\operatorname{PAF}\left(10^{-9}-10^{-6} \mathrm{M}\right)$ and its vehicle $(0.25 \%$ bovine serum albumin $)$ on the basal tone (a) and amplitude (b)/frequency (c) of spontaneous contractions in the isolated mouse urinary bladder smooth muscle shown in Fig. 3. Basal tone increases show basal tone changes before and after administration of PAF or its vehicle (a). Spontaneous contraction activities analyzed over 3 min during the following periods were calculated: immediately before administration of PAF or its vehicle (Ctrl, control); 7-10 $\mathrm{min}$ (10), 17-20 $\mathrm{min}$ (20), 27-30 $\mathrm{min}$ (30), 37-40 $\mathrm{min}$ (40), 47-50 $\mathrm{min}$ (50), and 57-60 min (60) after administration of PAF or its vehicle (b,c). Data are expressed as the means \pm SEM $\left[n=6\right.$ (vehicle), $n=5\left(10^{-9} \mathrm{M}\right)$, $\left.n=9\left(10^{-8} \mathrm{M}\right), n=14\left(10^{-7} \mathrm{M}\right), n=16\left(10^{-6} \mathrm{M}\right)\right] .{ }^{\star} P<0.05 ;{ }^{*} P<0.01$ vs. the corresponding vehicle value; ${ }^{\#} P<0.05$; ${ }^{\# \#} P<0.01$ vs. the corresponding control value (two-way ANOVA followed by Dunnett's test). PAF platelet-activating factor, $A C h$ acetylcholine.

PAF $\left(10^{-6} \mathrm{M}\right)$ on GP UBSM basal tone (Fig. 5c) and the amplitude (Fig. 5d) and frequency (Fig. 5e) of spontaneous contractile activities were almost completely suppressed by apafant $\left(10^{-5} \mathrm{M}\right)$ (Fig. $\left.5 \mathrm{~b}-\mathrm{e}\right)$.

Figure 6 shows typical experimental traces (Fig. 6a,b) and quantified results (Fig. 6c-e) of the effects of apafant $\left(3 \times 10^{-5} \mathrm{M}\right)$ on mouse UBSM basal tone (Fig. 6c), as well as the amplitude (Fig. 6d) and frequency (Fig. 6e) of spontaneous contractile activities enhanced by PAF $\left(10^{-6} \mathrm{M}\right)$. The enhancing effects of PAF $\left(10^{-6} \mathrm{M}\right)$ on mouse UBSM basal tone (Fig. 6c) and the amplitude (Fig. 6d) and frequency (Fig. 6e) of spontaneous contractile activities were very strongly suppressed by apafant $\left(3 \times 10^{-5} \mathrm{M}\right)$.

mRNA expressions of PAF receptor (Ptafr), LPCAT (Lpcat1, Lpcat2), and PAF-AH (Pafah1b3, Pafah2) in GP and mouse UB tissues. Figure 7 shows the relative mRNA expressions of PAF receptor (Ptafr), LPCAT (Lpcat1 and Lpcat2), and PAF-AH (Pafah1b3 and Pafah2) in GP (Fig. 7a) and mouse (Fig. 7b) UB tissues as assessed by quantitative reverse transcription PCR (RT-qPCR). All mRNA expression levels have been normalized to that of Gapdh. Ptafr is expressed in both GP and mouse UB tissues. LPCAT mRNA (Lpcat1, Lpcat2) and PAF-AH mRNA (Pafah1b3, Pafah2) are also expressed in GP and mouse UB tissues; however, the expression of Pafah2 is extremely low compared to that of Pafah $1 b 3$. 
a

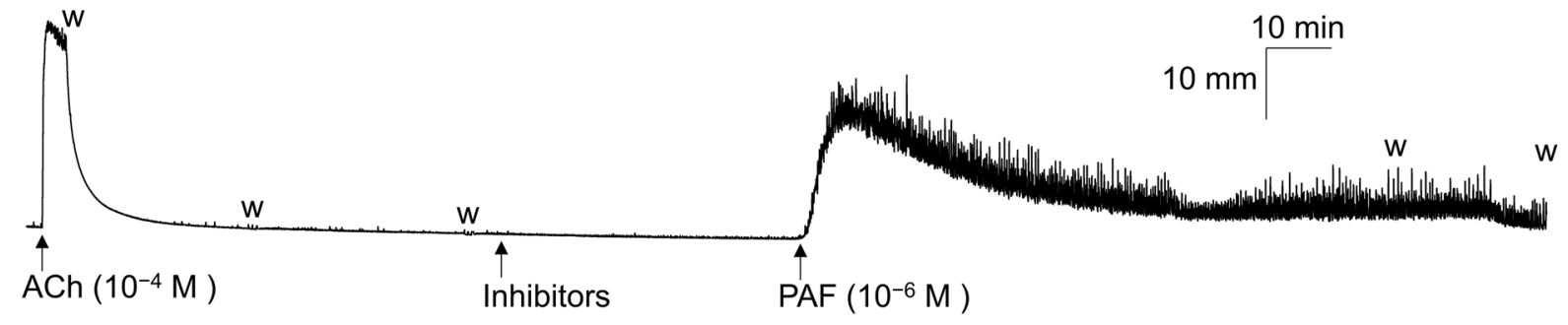

b

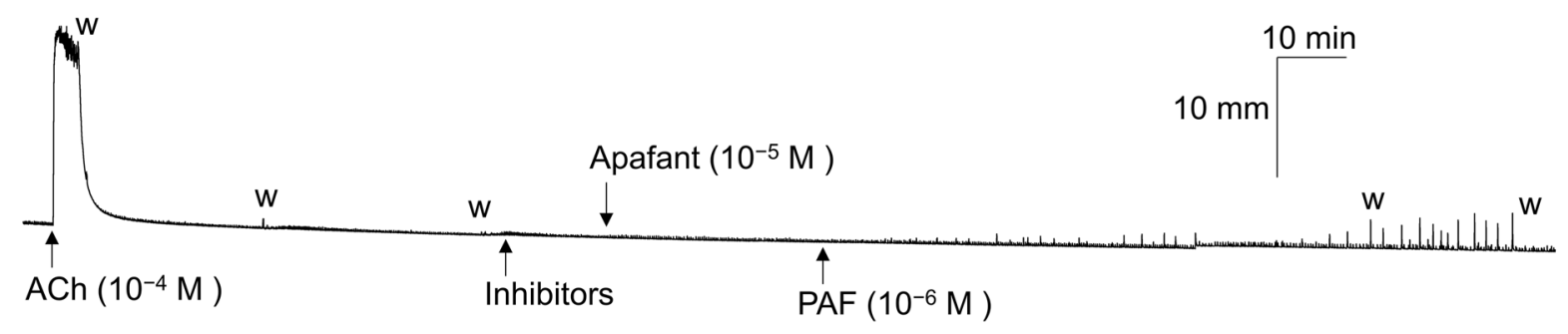

C

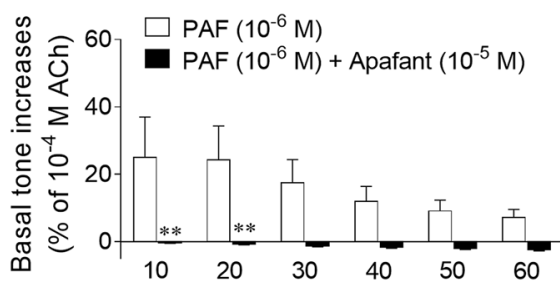

d

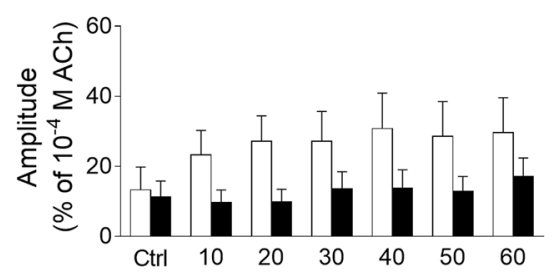

e

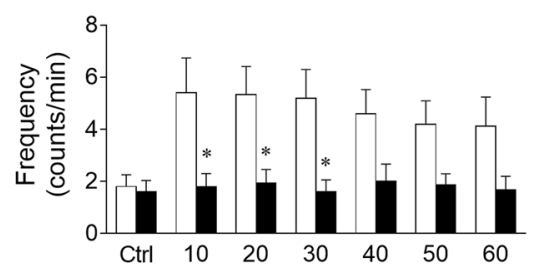

Figure 5. Representative traces (a,b) and summarized data (c-e) showing the effects of pretreatment of apafant $\left(10^{-5} \mathrm{M}, \mathbf{b}\right)$ on guinea pig urinary bladder smooth muscle basal tone increases (c) and amplitude (d)/ frequency (e) of spontaneous contraction activities enhanced by PAF $\left(10^{-6} \mathrm{M}\right)$. Basal tone increases show the basal tone changes before and after administration of PAF (c). Spontaneous contraction activities analyzed over 3 min during the following periods were calculated: immediately before administration of PAF (Ctrl, control); 7-10 $\mathrm{min}$ (10), 17-20 $\mathrm{min}$ (20), 27-30 $\mathrm{min}$ (30), 37-40 $\mathrm{min}$ (40), 47-50 $\mathrm{min}$ (50), and 57-60 min (60) after administration of PAF $(\mathbf{d}, \mathbf{e})$. Data are expressed as the means \pm SEM (each $n=5) .{ }^{\star} P<0.05 ;{ }^{* *} P<0.01$ vs. the corresponding PAF alone value (multiple $t$-tests). Inhibitors: atropine $\left(10^{-6} \mathrm{M}\right)$, suramin $\left(10^{-4} \mathrm{M}\right)$, phentolamine $\left(10^{-6} \mathrm{M}\right)$, propranolol $\left(10^{-6} \mathrm{M}\right)$, tetrodotoxin $\left(3 \times 10^{-7} \mathrm{M}\right)$, anti-foam $(0.5 \%)$, and bovine serum albumin $(0.25 \%) . w$ wash out, $P A F$ platelet-activating factor, $A C h$ acetylcholine.

\section{Discussion}

In this study, we found that PAF $\left(10^{-9}-10^{-6} \mathrm{M}\right)$ strongly enhanced the basal tone and spontaneous contractile activities (amplitude and frequency) of GP and mouse UBSM tissues in a concentration-dependent manner. The enhancing effects of PAF $\left(10^{-6} \mathrm{M}\right)$ on both UBSM contractile activities were very strongly suppressed by apafant pretreatment (GP: $10^{-5} \mathrm{M}$; mouse: $3 \times 10^{-5} \mathrm{M}$ ). PAF receptor (Ptafr), LPCAT (Lpcat1 and Lpcat2), and PAF-AH (Pafah1b3 and Pafah2) mRNAs were found to be expressed in GP and mouse UB tissues. These findings reveal that PAF strongly enhances contractile mechanical activities of UBSM tissues through the PAF receptor and suggest that the PAF-synthesizing and PAF-degrading system may exist in UBSM tissues. PAF may be both an endogenous UBSM constrictor and an endogenous mediator leading to detrusor overactivity.

ACh and ATP are the best-known endogenous UBSM constrictors. These neurotransmitters are released from nerve endings of the parasympathetic nervous system that innervates UBSM, and they play a physiologically important role in the UB micturition reflex. In fact, ACh and ATP are involved in the contractile responses induced by electrical field stimulation in isolated GP and mouse UBSM tissues ${ }^{25,26}$. Tachykinins (neurokinin A and substance P) are also known as endogenous UBSM contractile substances ${ }^{27}$. Although these substances induce contraction of isolated UBSM tissues, they are considered to promote the UB micturition reflex physiologically by affecting the central nervous system ${ }^{27}$. Thus, the peripheral physiological roles of tachykinins on UBSM contractile functions are still unclear. In recent years, prostanoids have also attracted attention as endogenous UBSM constrictors. Specifically, prostaglandin (PG) $\mathrm{A}_{2}, \mathrm{PGE}_{2}, \mathrm{PGF}_{2 \alpha}$, and thromboxane $\mathrm{A}_{2}$ strongly induce UBSM contractions and enhance spontaneous contractile activities ${ }^{28}$. PAF was reported to contract various SM tissues (tracheal and bronchial SMs ${ }^{8-10}$, uterine SMs from pregnant females ${ }^{15-17}$, and gastrointestinal SMs ${ }^{11-14}$ ). In this study, we found that PAF is able to potently contract isolated GP and mouse UBSM tissues and enhance their mechanical contractile activities. To the best of our knowledge, ours is the first report of the effect of PAF on UBSM contractile functions.

PAF was first identified as a substance produced and released from inflammatory cells ${ }^{1}$. Subsequent research revealed that PAF is synthesized not only by inflammatory cells but also by cells that are not directly involved 

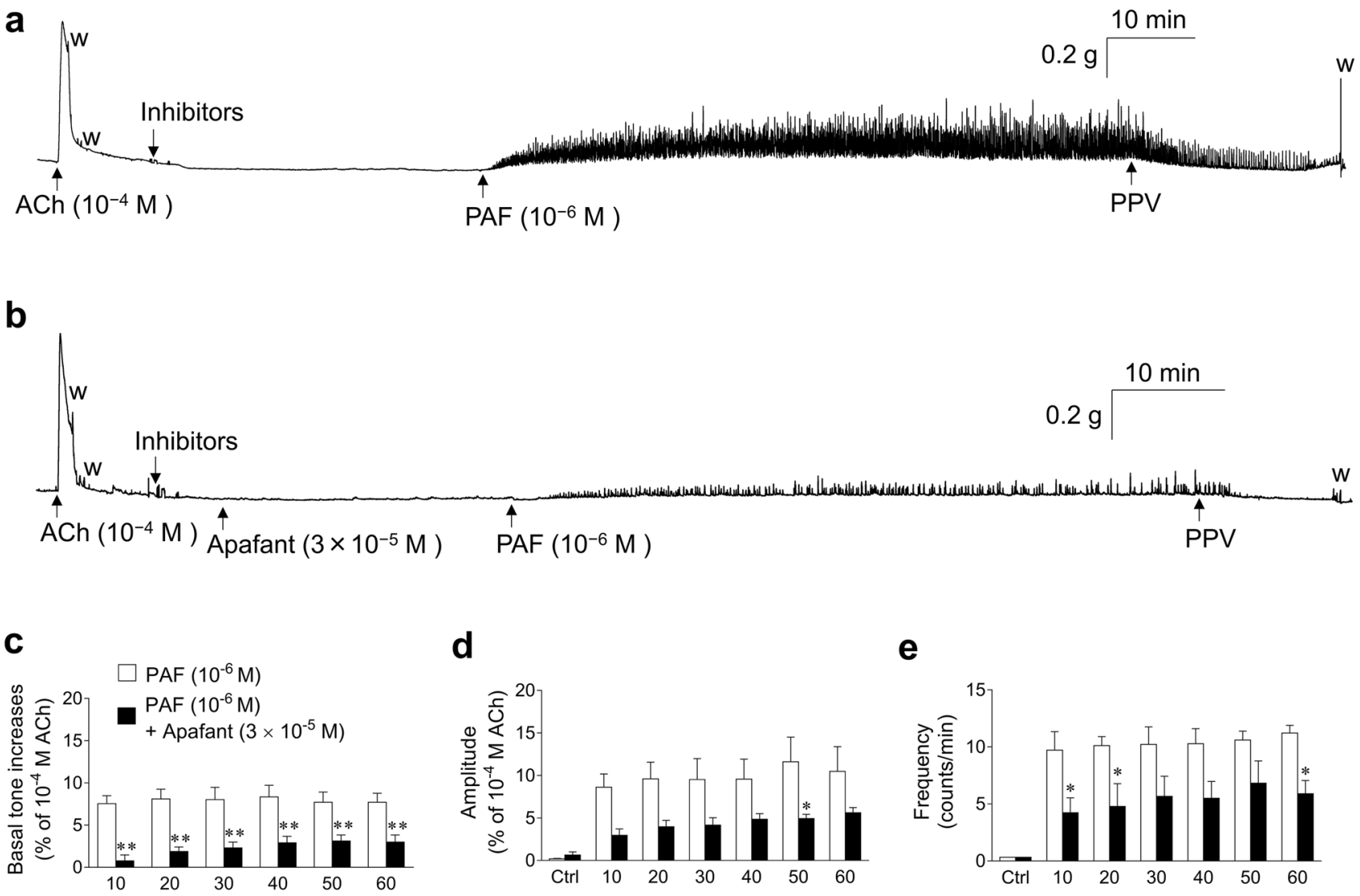

Figure 6. Representative traces (a,b) and summarized data (c-e) showing the effects of pretreatment of apafant $\left(3 \times 10^{-5} \mathrm{M}, \mathbf{b}\right)$ on mouse urinary bladder smooth muscle basal tone increases (c) and amplitude (d)/ frequency (e) of spontaneous contraction activities enhanced by PAF $\left(10^{-6} \mathrm{M}\right)$. Basal tone increases show the basal tone changes before and after administration of PAF (c). Spontaneous contraction activities analyzed over 3 min during the following periods were calculated: immediately before administration of PAF (Ctrl, control); 7-10 $\min (10), 17-20 \min (20), 27-30 \min (30), 37-40 \min (40), 47-50 \mathrm{~min}$ (50), and 57-60 $\min (60)$ after administration of PAF $(\mathbf{d}, \mathbf{e})$. Data are expressed as the means \pm SEM (each $n=5) .{ }^{\star} P<0.05 ;{ }^{*} P<0.01$ vs. the corresponding PAF alone value (multiple $t$-tests). Inhibitors: atropine $\left(10^{-6} \mathrm{M}\right)$, suramin $\left(10^{-4} \mathrm{M}\right)$, phentolamine $\left(10^{-6} \mathrm{M}\right)$, propranolol $\left(10^{-6} \mathrm{M}\right)$, tetrodotoxin $\left(3 \times 10^{-7} \mathrm{M}\right)$, anti-foam $(0.5 \%)$, and bovine serum albumin (0.25\%). $P P V$ papaverine $\left(10^{-4} \mathrm{M}\right), w$ wash out, $P A F$ platelet-activating factor, $A C h$ acetylcholine.

in inflammation, such as cardiomyocytes and endothelial cells ${ }^{18-20}$. Interestingly, most cells that synthesize PAF also express the PAF receptor ${ }^{18}$. The biosynthetic routes of PAF involve two different pathways, the remodeling pathway and the de novo pathway ${ }^{3,29}$. The remodeling pathway is a route that converts cell membrane lipid into the PAF precursor lyso-PAF. Specifically, alkylacyl phosphatidylcholines, a subclass of membrane phospholipids, are metabolized to lyso-PAF by phospholipase $\mathrm{A}_{2}\left(\mathrm{PLA}_{2}\right)$, and lyso-PAF is then converted to PAF via LPCAT ${ }^{3,29}$. In contrast, the de novo pathway is a route that converts ether lipid intermediates into PAF. It consists of three steps: (1) acetylation/acylation, (2) dephosphorylation, and (3) transfer of the phosphocholine moiety from CDP-choline to a diradylgycerol via alkylacetylglycerol dithiothreitol-insensitive cholinephosphotransferase ${ }^{3,29}$. After stimulating its target cells, PAF is rapidly hydrolyzed to biologically inactive lyso-PAF by PAF-AH, a PLA enzyme ${ }^{3,29}$. The remodeling pathway appears to be the main mechanism of PAF synthesis in stimulated neutrophils, monocytes, and eosinophils when inflammatory and allergic disorders occur, and the de novo pathway may play a role in the homeostatic functions of organs such as the brain and kidney ${ }^{3,29-32}$. In contrast, in endothelial cells, PAF is reported to be biosynthesized via the remodeling pathway ${ }^{3}$.

PAF increased the mechanical activity of GP UBSM more strongly than that of mouse UBSM. GP is often used as a research model for the human urinary tract, as its lower urinary tract anatomy and urodynamic profile of micturition are similar to those of humans ${ }^{24}$. Additionally, GP UB contains the contractile muscularis mucosae (SM) in addition to the detrusor SM, similar to the human UB, whereas mouse UB is deficient in the contractile muscularis mucosae ${ }^{33}$. Therefore, in GP UB, PAF could contract not only the detrusor SM but also muscularis mucosae, leading to a stronger increase in mechanical activity. However, mouse UB appeared to express higher levels of PAF receptor mRNA compared with GP UB. The appearance of stronger contractions in GP UB with lower PAF receptor mRNA expression compared with mouse UB with higher PAF receptor mRNA expression was not consistent with the general assumption that there is a correlation between the receptor mRNA expression levels and changes in SM contractile function. A reason for this phenomenon might be that the PAF-induced contractile response in mouse UBSM can be strongly affected by the suppressing factors. For example, the 


\section{a guinea pig}

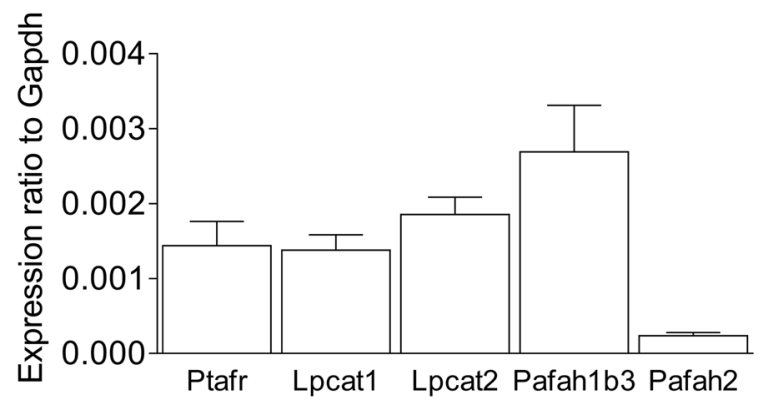

\section{b mouse}

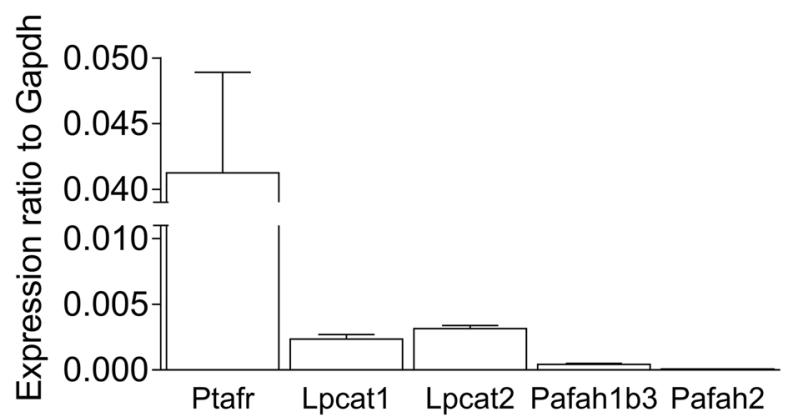

Figure 7. mRNA expression levels of PAF receptor (Ptafr), PAF-synthesizing enzymes (Lpcat1, Lpcat2), and PAF-degrading enzymes (Pafah1b3, Pafah2) in guinea pig (a) and mouse (b) urinary bladder tissues as assessed by RT-qPCR. The expression level of each mRNA is shown relative to the mRNA expression level of Gapdh, which is arbitrarily set as 1 . Data are expressed as the means \pm SEM $[n=8$ (a) and $n=7-10$ (b)]. PAF plateletactivating factor.

spontaneous contractile activity of the mouse bladder is considerably weaker than that of the GP UBSM (Figs. 1 and 3), and the large conductance calcium-activated $\mathrm{K}^{+}$channel (BK channel) was reported to strongly suppress the mouse UBSM spontaneous contraction ${ }^{34}$. Therefore, the PAF-induced contractile response might also be strongly suppressed by the BK channel; nevertheless, this hypothesis warrants further clarification in the future.

In GP UBSM, the enhancing effect of PAF $\left(10^{-6} \mathrm{M}\right)$ on basal tone persisted for $<60$ min and tended to start decreasing 20-30 min after PAF administration. This concentration of PAF may strongly stimulate the PAF receptor in GP UBSM, resulting in desensitization. Reportedly, repeated administration of PAF diminishes the contraction response induced by PAF in rat stomach $\mathrm{SM}^{11}$. Inflammation induced by infusion of trinitrobenzene sulfonic acid in GP ileum has also been reported to cause desensitization of PAF receptors. Desensitization of PAF receptors in the ileum depends on the duration of inflammation and correlates with PAF content in the ileum, suggesting that PAF receptor desensitization may play a protective role by preventing overstimulation of intestinal SM ${ }^{35}$. Therefore, in GP UBSM, excessive PAF stimulation might cause PAF receptor desensitization, which may have a protective effect on the UBSM. In addition, the mRNA expression level of the PAF-degrading enzyme (PAF-AH) was higher in the GP UB than in the mouse UB (Fig. 7). Therefore, another reason why the enhancing effect of PAF $\left(10^{-6} \mathrm{M}\right)$ in GP UBSM did not persist may be that PAF is more likely to be degraded in GP UB than in mouse UB.

PAF was reported to increase intracellular $\mathrm{Ca}^{2+}$ concentration in rat mesenteric vein and human uterine smooth muscle cells ${ }^{36,37}$. In human uterine smooth muscle cells, inositol trisphosphate was involved in the PAFinduced increase in intracellular $\mathrm{Ca}^{2+}$ concentration ${ }^{37}$. In rat stomach smooth muscles, the contractile response induced by PAF depends on $\mathrm{Ca}^{2+}$ influx from the extracellular fluid, wherein the underlying mechanism involves the nicardipine-sensitive $\mathrm{Ca}^{2+}$ influx pathway (voltage-gated $\mathrm{Ca}^{2+}$ channel) ${ }^{11}$; this pathway involved in the PAFinduced contractile responses of UBSM warrants further investigation.

Recently, the connection between PAF and chronic UB inflammatory responses caused by smoking has been reported. Exposure to cigarette smoke results in (1) increased PAF production and decreased PAF-AH activity in human and mouse UB microvascular endothelial cells ${ }^{21}$ and (2) increased PAF production and PAF receptor expression in human urothelial cells ${ }^{22}$. In addition, calcium-independent $\mathrm{PLA}_{2}\left(\mathrm{iPLA}_{2}\right)$ was reported to catalyze PAF biosynthesis in both UB microvascular endothelial cells and urothelial cells ${ }^{21,22}$. Due to long-term cigarette smoke exposure, both PAF expression and PAF receptor expression were increased in the UB of wild-type mice, whereas neither was detected in the UB of $\mathrm{iPLA}_{2}\left(\mathrm{iPLA}_{2} \beta\right)$-knockout mice ${ }^{22}$. In the present study, we detected the mRNA expression of PAF receptor (Ptafr), LPCAT (Lpcat1 and Lpcat2), and PAF-AH (Pafah1b3 and Pafah2) in both GP and mouse UB tissues. Our findings suggest that PAF is involved in the regulation of physiological contractile functions in both GP and mouse UB tissues, although it still cannot be concluded whether the UB 
epithelium, UBSM, or other cells express the abovementioned mRNA. This should be clarified in future studies. However, the following evidence suggests that PAF receptors are present at least in the GP UBSM: (1) the enhancing effects of PAF $\left(10^{-6} \mathrm{M}\right)$ on contractile activities were almost identical in epithelial-intact and epithelialremoved GP UB tissues (Supplementary Fig. 3) and (2) PAF receptor mRNA expression was also detected in epithelial-removed GP UB tissues (Supplementary Fig. 4).

As mentioned above, PAF may be involved in the pathogenesis of chronic inflammatory UB diseases caused by smoking, such as interstitial cystitis and bladder pain syndrome ${ }^{21,22}$. PAF may also be involved in bladder cancer caused by smoking; for example, PAF accumulation was significantly higher in isolated urothelial tissues from UB cancer patients than in normal human urothelial tissues, and PAF expression was markedly higher in highgrade tumors than in low-grade tumors ${ }^{23}$. Furthermore, the association between smoking and overactive bladder (OAB) has recently been reported. Namely, (1) the relative risk of OAB in males was higher for ex-smokers and current smokers than for non-smokers ${ }^{38}$, and (2) cigarette smoking is associated with OAB in females ${ }^{39}$. Thus, PAF might also be involved in the OAB caused by smoking. From this point of view, we highlight the potential role of PAF receptor antagonists as new therapeutic agents for the abovementioned smoking-caused UB diseases.

\section{Methods}

Animals. Male GPs (age 5-8 weeks old; weight 310-500 g; Kyudo Co., Ltd., Saga, Japan) and male mice (age 9-16 weeks old; weight 38-56 g; Japan SLC, Hamamatsu, Japan) were housed under controlled conditions $\left(20-22^{\circ} \mathrm{C}\right.$, relative air humidity $\left.50 \pm 5 \%\right)$ and a fixed $12 / 12 \mathrm{~h}$ light/dark cycle (08:00-20:00), with food and water available ad libitum. This study was approved by the Toho University Animal Care and Use Committee (approval number: 21-52-444) and was conducted in accordance with the guidelines of the Laboratory Animal Center of Faculty of Pharmaceutical Sciences, Toho University. This study was carried out in compliance with the ARRIVE guidelines.

Preparation of UBSM strips. GPs and mice were anesthetized using isoflurane inhalation and euthanized by exsanguination via the carotid artery. Thereafter, the UBs of GPs/mice were rapidly excised and immersed in modified/normal Locke-Ringer solution containing $(\mathrm{mM}) \mathrm{NaCl}, 154 ; \mathrm{KCl}, 5.63 ; \mathrm{CaCl}_{2}, 1.2 / 2.16 ; \mathrm{MgCl}_{2}, 2.1$; $\mathrm{NaHCO}_{3}, 5.95$; glucose, 2.78. After removing surrounding adipose and connective tissues and the UB trigone, the UB was opened with a longitudinal incision, and UBSM strips (GP: approximately $2 \mathrm{~mm}$ in width $\times 20 \mathrm{~mm}$ in length; mouse: approximately $1 \mathrm{~mm}$ in width $\times 10 \mathrm{~mm}$ in length) were prepared. UB epithelial cells were not removed in this study unless otherwise stated.

Measurement of UBSM basal tone and spontaneous contractile activities. The GP and mouse UBSM strips were suspended under a resting tone of $1.0 \mathrm{~g}$ and resting tension of $0.5 \mathrm{~g}$, respectively, in a $20 \mathrm{~mL}$ organ bath filled with modified/normal Locke-Ringer solution at $32 \pm 1.0^{\circ} \mathrm{C}$ and bubbled with a mixture of $95 \%$ $\mathrm{O}_{2}$ and $5 \% \mathrm{CO}_{2}$. GP UBSM length changes were isotonically recorded with isotonic transducers and amplifiers (IT-300/IT-AM-300, Physio-Tech Co., Ltd., Tokyo, Japan), and mouse UBSM tension changes were isometrically recorded with isometric transducers and amplifiers (TB-612T/AP-620G, Nihon Kohden, Tokyo, Japan). All data were recorded using PowerLab ${ }^{\text {TM }}$ and LabChart ${ }^{\text {Tn }}$ (Version 7) software (ADInstruments Pty. Ltd., Bella Vista, NSW, Australia).

The UBSM strips were equilibrated for $\geq 20 \mathrm{~min}$ and then contracted using ACh $\left(10^{-4} \mathrm{M}\right)$ at least 3 times at $10 \mathrm{~min}$ intervals. After UBSM basal tone stabilized, phentolamine $\left(10^{-6} \mathrm{M}\right.$, an $\alpha$-adrenoceptor antagonist), propranolol $\left(10^{-6} \mathrm{M}\right.$, a $\beta$-adrenoceptor antagonist), atropine $\left(10^{-6} \mathrm{M}\right.$, a muscarinic receptor antagonist), suramin $\left(10^{-4} \mathrm{M}\right.$, a purine P2X receptor antagonist), TTX $\left(3 \times 10^{-7} \mathrm{M}\right.$, a Na ${ }^{+}$channel inhibitor $)$, anti-foam $(0.5 \%)$, and BSA $(0.25 \%)$ were administered, and the strips were incubated for $30 \mathrm{~min}$. This inhibitor cocktail was used to eliminate the possible effects of peripheral nerve-derived neurotransmitters. As shown in Supplementary Fig. 5, the contractions induced by ACh $\left(3 \times 10^{-6} \mathrm{M}\right)$ were completely suppressed by atropine $\left(10^{-6} \mathrm{M}\right)$ in both GP (Supplementary Fig. 5a) and mouse (Supplementary Fig. 5e) UBSMs. Moreover, the relaxations induced by NA $\left(10^{-6} \mathrm{M}\right)$ in the presence of bethanechol $\left(3 \times 10^{-6} \mathrm{M}\right)$ and phentolamine $\left(10^{-6} \mathrm{M}\right)$ were completely suppressed by propranolol $\left(10^{-6} \mathrm{M}\right.$ ) (Supplementary Fig. $\left.5 \mathrm{~d}, \mathrm{~h}\right)$. In addition, the contractions induced by ATP $\left(10^{-4} \mathrm{M} / 3 \times 10^{-4} \mathrm{M}\right)$ were strongly suppressed by suramin $\left(10^{-4} \mathrm{M}\right)$ (Supplementary Fig. $5 \mathrm{~b}$,f). Since NA $\left(10^{-6} \mathrm{M}\right)$ and phenylephrine $\left(10^{-6} \mathrm{M}\right.$, a selective $\alpha_{1}$-adrenoceptor agonist) did not contract GP or mouse UBSMs in the presence of propranolol $\left(10^{-6} \mathrm{M}\right.$ ) (Supplementary Fig. $5 \mathrm{c}, \mathrm{g}$ ), substantial involvement of $\alpha_{1}$-adrenoceptor in both UBSMs was considered negligible. Phentolamine $\left(10^{-6} \mathrm{M}\right)$ was reported to strongly suppress the NA-induced blood vessel contractions ${ }^{40}$. We previously confirmed that TTX almost completely eliminates ACh- and ATPmediated contractile responses elicited by electrical field stimulations in both GP and mouse UBSMs ${ }^{25,26}$.

All the experiments were performed in the presence of indomethacin $\left(3 \times 10^{-6} \mathrm{M}\right.$, a cyclooxygenase inhibitor $)$ to eliminate the effects of endogenous prostanoids.

Effects of PAF on GP and mouse UBSM basal tone and spontaneous contractile activities. After the procedures described in the previous section, PAF $\left(10^{-9}-10^{-6} \mathrm{M}\right)$ or its vehicle $(0.25 \% \mathrm{BSA})$ was administered in the bath medium, and the strips were incubated for $60 \mathrm{~min}$. Afterward, the GP UBSM strips were washed with modified Locke-Ringer solution, and the mouse UBSM strips were relaxed with papaverine (PPV, $\left.10^{-4} \mathrm{M}\right)$. Reportedly, PPV induces the contractile response in GP $\mathrm{UBSM}^{41}$. Herein, we confirmed that PPV enhanced spontaneous contractile activity and did not suppress the contractile response by PAF, as shown in Supplementary Fig. 1. Therefore, we performed the wash-out operation without using PPV in GP UBSM. 


\begin{tabular}{|c|c|c|}
\hline Animal species & Gene symbol & Sequence $\left(5^{\prime}-3^{\prime}\right)$ \\
\hline \multirow{2}{*}{ Guinea pig } & \multirow{2}{*}{ Ptafr } & GAAGAAGCCGAGCACAATGC \\
\hline & & ATCAAGACTGCTCAGGCCAC \\
\hline \multirow{2}{*}{ Guinea pig } & \multirow{2}{*}{ Lpcat1 } & TGATTGCCCTGTCAGTCGTG \\
\hline & & CCAGAGCGGTCCTGAGAATG \\
\hline \multirow{2}{*}{ Guinea pig } & \multirow{2}{*}{ Lpcat2 } & ACGTTGCCTATGGAAGCTGG \\
\hline & & TCGAGGCACTGGCAATAGAC \\
\hline \multirow{2}{*}{ Guinea pig } & \multirow{2}{*}{ Pafahlb3 } & ACCCACTCTCGGCTTTTCAG \\
\hline & & ACGACTTCGGGTTCCTTGTC \\
\hline \multirow{2}{*}{ Guinea pig } & \multirow{2}{*}{ Pafah2 } & TCCTGGGTGGTTTCTCATTTCC \\
\hline & & \begin{tabular}{|l|} 
CTGGCTGGTCCCCATCTTATC \\
\end{tabular} \\
\hline \multirow{2}{*}{ Guinea pig } & \multirow{2}{*}{ Gapdh } & ACGGATTTGGCCGTATTGGA \\
\hline & & CCATTCTCAGCCTTGACGGT \\
\hline \multirow{2}{*}{ Mouse } & \multirow{2}{*}{ Ptafr } & CGAGGGCGACTGGATTCTAC \\
\hline & & CAAAGAGATGCCACGCTTGC \\
\hline \multirow{2}{*}{ Mouse } & \multirow{2}{*}{ Lpcat1 } & GGACCTGGAGCGTTGAAAATC \\
\hline & & \begin{tabular}{|l|} 
CATGACACGCCTCACATTGC \\
\end{tabular} \\
\hline \multirow{2}{*}{ Mouse } & \multirow{2}{*}{ Lpcat2 } & TGGCCCCAGATACTAGTTTTCC \\
\hline & & \begin{tabular}{|l} 
TATAGCCTTGCCAGGTCCAG \\
\end{tabular} \\
\hline \multirow{2}{*}{ Mouse } & \multirow{2}{*}{ Pafahlb3 } & CCGTCCACTCTGGGTTGTG \\
\hline & & CGCAGACTAGAAACCGTCAC \\
\hline \multirow{2}{*}{ Mouse } & \multirow{2}{*}{ Pafah2 } & TTCTGTGTTCTGTCTTCCAGCC \\
\hline & & \begin{tabular}{|l|} 
CTGTACTCGTAGCGGGGAATC \\
\end{tabular} \\
\hline \multirow{2}{*}{ Mouse } & \multirow{2}{*}{ Gapdh } & GATGACATCAAGAAGGTGGTGA \\
\hline & & \begin{tabular}{|l|l} 
TGCTGTAGCCGTATTCATTGTC \\
\end{tabular} \\
\hline
\end{tabular}

Table 1. Primers used for RT-qPCR.

Effects of apafant on UBSM basal tone and spontaneous contractile activities enhanced by PAF. Apafant (a PAF receptor antagonist, GP: $10^{-5} \mathrm{M}$; mouse: $3 \times 10^{-5} \mathrm{M}$ ) was administered in the bath medium concomitantly with the inhibitor cocktail described in "Measurement of UBSM basal tone and spontaneous contractile activities". Afterward, the effects of PAF $\left(10^{-6} \mathrm{M}\right)$ were determined as described in "Effects of PAF on GP and mouse UBSM basal tone and spontaneous contractile activities".

RT-qPCR of mRNA expression of PAF receptor (Ptafr), LPCAT (Lpcat1, Lpcat2), and PAF-AH (Pafah1b3, Pafah2). Total RNA was extracted from isolated GP and mouse UBs using the acid guanidinium thiocyanate-phenol-chloroform method ${ }^{42}$. The extracted total RNA was treated with deoxyribonuclease (Nippon Gene Co. Ltd., Tokyo, Japan) at $37^{\circ} \mathrm{C}$ for $30 \mathrm{~min}$. Phenol-chloroform extraction was performed after contaminating DNA removal, followed by ethanol precipitation. The RNA pellets were dissolved in diethyl pyrocarbonate-treated water. First-strand cDNA was synthesized by reverse transcription with $1 \mu \mathrm{g}$ total RNA per $20 \mu \mathrm{L}$ reaction mixture using the ReverTra Ace qPCR RT Master Mix with gDNA Remover (TOYOBO Co., Ltd., Osaka, Japan) according to the manufacturer's protocol.

RT-qPCR was performed using the THUNDERBIRD ${ }^{\circ}$ Next SYBR ${ }^{\circ}$ qPCR Mix (TOYOBO Co. Ltd.) according to the manufacturer's protocol. The primers used in this study are shown in Table 1. PCR and DNA amplification (fluorescence intensity) measurements were performed using a 7500 Fast Real-Time PCR System (Applied Biosystems, Waltham, MA, USA). The thermal cycler parameters were set at $95^{\circ} \mathrm{C}$ for 2 min, followed by 40 cycles of denaturation at $95^{\circ} \mathrm{C}$ for $15 \mathrm{~s}$, annealing at $60^{\circ} \mathrm{C}$ for $30 \mathrm{~s}$, and elongation at $72^{\circ} \mathrm{C}$ for $35 \mathrm{~s}$. DNA amplification (fluorescence intensity) was measured at each elongation step. After PCR completion, the melting curves of each PCR product were measured from $60-95^{\circ} \mathrm{C}$. The data were analyzed using Sequence Detection Software Version 1.4 (Applied Biosystems). Samples that did not reach the fluorescence intensity threshold after 40 cycles of amplification were considered to have no detectable mRNA expression. The mRNA expression level of each gene was calculated as a relative value, normalized to the mRNA expression level of the glyceraldehyde 3-phosphate dehydrogenase gene (Gapdh), which was set to 1 .

Drugs. The following drugs were used in this study: PAF C-16 and apafant (Cayman Chemical, Ann Arbor, MI, USA); TTX, suramin sodium and anti-foam (FUJIFILM Wako Pure Chemical Co., Osaka, Japan.); phentolamine mesylate (Novartis Pharma KK, Tokyo, Japan); DL-propranolol hydrochloride, atropine sulfate salt monohydrate, and indomethacin (Sigma-Aldrich Co., St. Louis, MO, USA); and BSA (fatty acid free, pH 7.0; Nacalai Tesque Inc., Kyoto, Japan).

PAF was dissolved in ethanol (EtOH) to prepare a stock solution of $2 \times 10^{-3} \mathrm{M}$ and stored at $-80^{\circ} \mathrm{C}$. When using PAF, the EtOH solvent was evaporated, and PAF was redissolved and diluted with $0.25 \%$ BSA to prepare 
solutions of $2 \times 10^{-4}-2 \times 10^{-7} \mathrm{M}$. Indomethacin was dissolved in EtOH to prepare a stock solution of $10^{-2} \mathrm{M}$. All other drugs were dissolved and diluted with distilled water.

Data analysis. UBSM basal tone and amplitude/frequency of spontaneous contraction activities were analyzed using the cyclic measurement mode of LabChart 7, considering the minimum point of each spontaneous contraction event after PAF application as the baseline level. The minimum average amplitude (basal tone), average amplitude, and the total number of UBSM spontaneous contractile activities over 3 min during the following periods were calculated: immediately before administration of PAF (control) and 7-10 min, 17-20 min, 27-30 $\mathrm{min}, 37-40 \mathrm{~min}, 47-50 \mathrm{~min}$, and 57-60 min after administration of PAF. For these analyses, the cutoff value was set at one third of the largest spontaneous contraction immediately before administration of PAF for $3 \mathrm{~min}$ (GP) or $1 \%$ of the third $10^{-4} \mathrm{M}$ ACh-induced contraction described in "Measurement of UBSM basal tone and spontaneous contractile activities" (mouse). Basal tone increases show the basal tone changes before and after administrations of PAF. UBSM basal tone increases and amplitude of spontaneous contractile activities are shown as relative values, with the third $10^{-4} \mathrm{M}$ ACh-induced contraction of the procedure described in "Measurement of UBSM basal tone and spontaneous contractile activities" set as 100\%. The frequency of UBSM spontaneous contractile activities (counts/min) was calculated by dividing the total number of spontaneous contractile activities over $3 \mathrm{~min}$ by $3 \mathrm{~min}$.

Data are expressed as the means \pm standard error of the mean (SEM), where $n$ refers to the number of experiments. Statistical analyses were carried out with two-way ANOVA followed by Dunnett's tests or multiple $t$-tests using GraphPad Prism ${ }^{\text {Tx }}$ (Version 6) (GraphPad Software, Inc., San Diego, CA, USA). All statistical analyses were conducted with a significance level of $\alpha=0.05(P<0.05)$.

\section{Data availability}

The data that support the findings of this study are available from the corresponding author, $\mathrm{KO}$, upon reasonable request.

Received: 20 November 2021; Accepted: 31 January 2022

Published online: 17 February 2022

\section{References}

1. Benveniste, J., Henson, P. M. \& Cochrane, C. G. Leukocyte-dependent histamine release from rabbit platelets. The role of IgE, basophils, and a platelet-activating factor. J. Exp. Med. 136, 1356-1377. https://doi.org/10.1084/jem.136.6.1356 (1972).

2. Hanahan, D. J., Demopoulos, C. A., Liehr, J. \& Pinckard, R. N. Identification of platelet activating factor isolated from rabbit basophils as acetyl glyceryl ether phosphorylcholine. J. Biol. Chem. 255, 5514-5516. https://doi.org/10.1016/S0021-9258(19)70658-9 (1980).

3. Prescott, S. M., Zimmerman, G. A. \& McIntyre, T. M. Platelet-activating factor. J. Biol. Chem. 265, 17381-17384. https://doi.org/ 10.1016/S0021-9258(18)38167-5 (1990).

4. Kasuya, Y., Masuda, Y. \& Shigenobu, K. Possible role of endothelium in the vasodilator response of rat thoracic aorta to platelet activating factor (PAF). J. Pharmacobio-Dyn. 7, 138-142. https://doi.org/10.1248/bpb1978.7.138 (1984).

5. Shigenobu, K., Masuda, Y., Tanaka, Y. \& Kasuya, Y. Platelet activating factor analogues: Lack of correlation between their activities to produce hypotension and endothelium-mediated vasodilation. J. Pharmacobio-Dyn. 8, 128-133. https://doi.org/10.1248/bpb19 78.8.128 (1985).

6. Chiba, Y., Mikoda, N., Kawasaki, H. \& Ito, K. Endothelium-dependent relaxant action of platelet activating factor in the rat mesenteric artery. Naunyn Schmiedebergs Arch. Pharmacol. 341, 68-73. https://doi.org/10.1007/BF00195060 (1990).

7. Gao, Y., Zhou, H. \& Raj, J. U. PAF induces relaxation of pulmonary arteries but contraction of pulmonary veins in the ferret. Am. J. Physiol. 269, H704-H709. https://doi.org/10.1152/ajpheart.1995.269.2.H704,Pubmed:7653635 (1995).

8. Jancar, S., Thériault, P., Braquet, P. \& Sirois, P. Comparative effects of platelet activating factor, leukotriene $\mathrm{D}_{4}$ and histamine on guinea pig trachea, bronchus and lung parenchyma. Prostaglandins 33, 199-208. https://doi.org/10.1016/0090-6980(87)90006-2 (1987).

9. Chand, N., Diamantis, W. \& Sofia, R. D. Effect of paf-acether on isoprenaline-induced relaxation in isolated tracheal segments of rats and guinea pigs. Eur. J. Pharmacol. 158, 135-137. https://doi.org/10.1016/0014-2999(88)90262-2 (1988).

10. Johnson, P. R., Black, J. L. \& Armour, C. L. Platelet-activating factor-induced contraction of human isolated bronchus. Eur. Respir. J. 5, 970-974 (1992).

11. Kamata, K., Arai, Y. \& Kasuya, Y. Mechanism of the contractile response to platelet-activating factor (PAF) of the rat stomach fundus. I. PAF-induced contractile response and calcium mobilization. Gen. Pharmacol. 24, 1331-1336. https://doi.org/10.1016/ 0306-3623(93)90415-t (1993).

12. Findlay, S. R., Lichtenstein, L. M., Hanahan, D. J. \& Pinckard, R. N. Contraction of guinea pig ileal smooth muscle by acetyl glyceryl ether phosphorylcholine. Am. J. Physiol. 241, C130-C133. https://doi.org/10.1152/ajpcell.1981.241.3.C130 (1981).

13. Jeanneton, O., Delvaux, M., Botella, A., Frexinos, J. \& Bueno, L. Platelet-activating factor (PAF) induces a contraction of isolated smooth muscle cells from guinea pig ileum: Intracellular pathway involved. J. Pharmacol. Exp. Ther. 267, 31-37 (1993).

14. Tokumura, A., Yube, N., Terao, M. \& Tsukatani, H. Antagonism of platelet-activating factor in isolated rat colon: Possible mechanism. Lipids 26, 1344-1346. https://doi.org/10.1007/BF02536563 (1991).

15. Tetta, C. et al. Platelet-activating factor contracts human myometrium in vitro. Proc. Soc. Exp. Biol. Med. 183, 376-381. https:// doi.org/10.3181/00379727-183-42435 (1986).

16. Montrucchio, G. et al. In vitro contractile effect of platelet-activating factor on guinea-pig myometrium. Prostaglandins 32, 539-554. https://doi.org/10.1016/0090-6980(86)90036-5 (1986).

17. Kim, B. K., Ozaki, H., Lee, S. M. \& Karaki, H. Increased sensitivity of rat myometrium to the contractile effect of platelet activating factor before delivery. Br. J. Pharmacol. 115, 1211-1214. https://doi.org/10.1111/j.1476-5381.1995.tb15027.x (1995).

18. Pałgan, K. \& Bartuzi, Z. Platelet activating factor in allergies. Int. J. Immunopathol. Pharmacol. 28, 584-589. https://doi.org/10. $1177 / 0394632015600598(2015)$.

19. Whatley, R. E., Zimmerman, G. A., McIntyre, T. M. \& Prescott, S. M. Lipid metabolism and signal transduction in endothelial cells. Prog. Lipid Res. 29, 45-63. https://doi.org/10.1016/0163-7827(90)90005-6 (1990).

20. Janero, D. R. \& Burghardt, C. Production and release of platelet-activating factor by the injured heart-muscle cell (cardiomyocyte). Res. Commun. Chem. Pathol. Pharmacol. 67, 201-218 (1990). 
21. Marentette, J., Kolar, G. \& McHowat, J. Increased susceptibility to bladder inflammation in smokers: Targeting the PAF-PAF receptor interaction to manage inflammatory cell recruitment. Physiol. Rep. 3, e12641. https://doi.org/10.14814/phy2.12641 (2015).

22. Kispert, S. E. et al. Cigarette smoke-induced urothelial cell damage: Potential role of platelet-activating factor. Physiol. Rep. $\mathbf{5}$, e13177. https://doi.org/10.14814/phy2.13177 (2017).

23. Kispert, S., Marentette, J. \& McHowat, J. Cigarette smoking promotes bladder cancer via increased platelet-activating factor. Physiol. Rep. 7, e13981. https://doi.org/10.14814/phy2.13981 (2019).

24. Brown, C. \& Mans, C. Urethral catheterization of the male guinea pig (Cavia porcellus). Lab. Anim. (NY) 36, 20-21. https://doi. org/10.1038/laban0707-20 (2007).

25. Obara, K., Kobayashi, Y., Chino, D. \& Tanaka, Y. Effect of distigmine on the contractile response of guinea pig urinary bladder to electrical field stimulation. Eur. J. Pharmacol. 809, 209-214. https://doi.org/10.1016/j.ejphar.2017.05.031 (2017).

26. Obara, K., Kobayashi, Y., Chino, D. \& Tanaka, Y. Effects of distigmine on electrical field stimulation-induced contraction of mouse urinary bladder smooth muscles. Pharmacology 99, 106-113. https://doi.org/10.1159/000452222 (2017).

27. Lecci, A. \& Maggi, C. A. Tachykinins as modulators of the micturition reflex in the central and peripheral nervous system. Regul. Pept. 101, 1-18. https://doi.org/10.1016/S0167-0115(01)00285-3 (2001).

28. Ou, G. et al. Prostanoid TP receptor stimulation enhances contractile activities in guinea pig urinary bladder smooth muscle through activation of $\mathrm{Ca}^{2+}$ entry channels: Potential targets in the treatment of urinary bladder contractile dysfunction. Life Sci. 287, 120130. https://doi.org/10.1016/j.lfs.2021.120130 (2021).

29. Snyder, F. Platelet-activating factor and related acetylated lipids as potent biologically active cellular mediators. Am. J. Physiol. 259, C697-C708. https://doi.org/10.1152/ajpcell.1990.259.5.C697 (1990).

30. Schlondorff, D. \& Neuwirth, R. Platelet-activating factor and the kidney. Am. J. Physiol. 251, F1-F11. https://doi.org/10.1152/ajpre nal.1986.251.1.F1 (1986).

31. Francescangeli, E., Boila, A. \& Goracci, G. Properties and regulation of microsomal PAF-synthesizing enzymes in rat brain cortex. Neurochem. Res. 25, 705-713. https://doi.org/10.1023/a:1007523422825 (2000).

32. Baker, R. R. Enzymes of platelet activating factor synthesis in brain. Neurochem. Res. 20, 1345-1351. https://doi.org/10.1007/BF009 92510 (1995).

33. Mitsui, R. et al. Contractile elements and their sympathetic regulations in the pig urinary bladder: A species and regional comparative study. Cell Tissue Res. 379, 373-387. https://doi.org/10.1007/s00441-019-03088-6 (2020).

34. Petkov, G. V. et al. Betal-subunit of the $\mathrm{Ca}^{2+}$-activated $\mathrm{K}^{+}$channel regulates contractile activity of mouse urinary bladder smooth muscle. J. Physiol. 537, 443-452. https://doi.org/10.1111/j.1469-7793.2001.00443.x (2001).

35. Jeanneton, O. et al. Correlation of desensitisation of platelet activating factor (PAF) receptors with intensity of inflammation and intestinal PAF content during experimental ileitis in guinea pig. Gut 43, 356-364. https://doi.org/10.1136/gut.43.3.356 (1998).

36. Claing, A., Shbaklo, H., Plante, M., Bkaily, G. \& D’Orléans-Juste, P. Comparison of the contractile and calcium-increasing properties of platelet-activating factor and endothelin-1 in the rat mesenteric artery and vein. Br. J. Pharmacol. 135, 433-443. https:// doi.org/10.1038/sj.bjp.0704441 (2002).

37. Molnár, M., Rigó, J. Jr. \& Hertelendy, F. Signal transduction in human myometrial cells. Acta Physiol. Hung. 84, 89-97 (1996)

38. Kawahara, T., Ito, H. \& Uemura, H. The impact of smoking on male lower urinary tract symptoms (LUTS). Sci. Rep. 10, 20212. https://doi.org/10.1038/s41598-020-77223-7 (2020).

39. Madhu, C., Enki, D., Drake, M. J. \& Hashim, H. The functional effects of cigarette smoking in women on the lower urinary tract. Urol. Int. 95, 478-482. https://doi.org/10.1159/000438928 (2015).

40. Muramatsu, I., Ohmura, T., Kigoshi, S., Hashimoto, S. \& Oshita, M. Pharmacological subclassification of alpha 1-adrenoceptors in vascular smooth muscle. Br. J. Pharmacol. 99, 197-201. https://doi.org/10.1111/j.1476-5381.1990.tb14678.x (1990).

41. Haruno, A. Effects of propiverine hydrochloride on the spontaneous contractions of isolated guinea-pig urinary bladder strip and rhythmic urinary bladder contractions of anesthetized dog. Arzneimittelforschung 42, 1459-1461 (1992).

42. Chomczynski, P. \& Sacchi, N. Single-step method of RNA isolation by acid guanidinium thiocyanate-phenol-chloroform extraction. Anal. Biochem. 162, 156-159. https://doi.org/10.1006/abio.1987.9999 (1987).

\section{Acknowledgements}

The authors would like to thank Ms. Nana Yamada for her expert technical assistance. This work was supported in part by the JSPS KAKENHI Grants-in-Aid for Scientific Research (C) (20K11519 to Y.T. and 21K11686 to K.O.) and Grants-in-Aid for Early-Career Scientists (21K17666 to K.Y.).

\section{Author contributions}

Conceptualization: G.L., K.Y., K.O., Y.T. Investigation: G.L., M.K., K.Y. Formal analysis: G.L., M.K., K.Y., K.O. Writing—original draft: G.L. Writing—review and editing: K.Y., K.O., Y.T. Funding acquisition: K.Y., K.O., Y.T.

\section{Competing interests}

The authors declare no competing interests.

Additional information

Supplementary Information The online version contains supplementary material available at https://doi.org/ 10.1038/s41598-022-06535-7.

Correspondence and requests for materials should be addressed to K.O.

Reprints and permissions information is available at www.nature.com/reprints.

Publisher's note Springer Nature remains neutral with regard to jurisdictional claims in published maps and institutional affiliations. 
(c) (i) Open Access This article is licensed under a Creative Commons Attribution 4.0 International cc) License, which permits use, sharing, adaptation, distribution and reproduction in any medium or format, as long as you give appropriate credit to the original author(s) and the source, provide a link to the Creative Commons licence, and indicate if changes were made. The images or other third party material in this article are included in the article's Creative Commons licence, unless indicated otherwise in a credit line to the material. If material is not included in the article's Creative Commons licence and your intended use is not permitted by statutory regulation or exceeds the permitted use, you will need to obtain permission directly from the copyright holder. To view a copy of this licence, visit http://creativecommons.org/licenses/by/4.0/.

(C) The Author(s) 2022 